Research Papers, part of a Special Feature on Conservation of Grassland Birds: Causes and

Consequences of Population Declines

\title{
Demography of Female Greater Prairie-Chickens in Unfragmented Grasslands in Kansas
}

\section{Démographie de femelles Tétras des prairies dans des prairies non fragmentées du Kansas}

\author{
$\underline{\text { Jacqueline K. Augustine }}^{1}$ and Brett K. Sandercock ${ }^{2}$
}

\begin{abstract}
Populations of Greater Prairie-Chickens (Tympanuchus cupido) have been declining because of loss and fragmentation of tallgrass prairie habitats, and management plans require contemporary demographic data. Our objectives were to determine whether maternal nutrition or predation were determinants of nesting success and female survival. We captured and radio-marked 43 females at four leks in natural, unfragmented prairie during a 4-year study. Reproductive potential was high because females laid large clutches $(10.9 \pm 0.3$ eggs, $n=24)$, renested following clutch loss $(22.2 \%, n=27$ females $)$, and had high egg viability $(88.6 \pm 5.0 \%$ of eggs hatched; $n=7$ nests), but reproductive traits were not correlated with female morphometrics (mass, or tarsus and keel lengths). Daily survival rate of nests was low $(0.928$, $n=34$ nests) resulting in a predicted nest success rate of $7.4 \%$ for a 35 -day exposure period. We used known fate models to estimate weekly survival from telemetry data for 40 females. Weekly survival was 0.970 and the extrapolated survival rate for the 6-month breeding season was $45.7 \%$. Using time-sincemarking Cormack-Jolly-Seber models for live encounter data to control for transience, annual apparent survival was $0.277 \pm 0.081 \mathrm{SE}$ for 55 marked females after initial capture, and $0.424 \pm 0.139$ during subsequent intervals. Survival of females was 1.6 to 2.0 times higher during the nonbreeding season than the breeding season, presumably because females are susceptible to predation during incubation and broodrearing. Predation of nests and females may be the main demographic factors limiting population viability because predation, and not maternal nutrition, accounted for unexpectedly low nesting success and breeding season survival of Greater Prairie-Chickens in natural habitats. Future research should investigate rangeland practices that increase residual nesting cover or reduce predator impacts.
\end{abstract}

RÉSUMÉ. Les populations de Tétras des prairies (Tympanuchus cupido) sont en déclin en raison de la perte et de la fragmentation des milieux de prairie à grandes graminées. Les plans de gestion doivent donc s'appuyer sur des données démographiques contemporaines. L'objectif de cette étude était de déterminer si l'alimentation des femelles et la prédation sont des facteurs importants du succès de reproduction et de la survie des femelles. Nous avons capturé et muni de radios 43 femelles provenant de quatre arènes dans des prairies naturelles non fragmentées, au cours d'une étude de quatre ans. Le potentiel de reproduction était élevé étant donné que les femelles produisaient de grosses couvées (10,9 $\pm 0,3$ œufs, $n=24)$, qu'elles pouvaient renicher lorsque la première avait échoué $(22,2 \%, n=27$ femelles) et que la viabilité des œufs était élevée (88,6 $\pm 5,0 \%$ d'œufs éclos; $n=7$ nids), mais ces paramètres de reproduction n'étaient pas corrélés avec les mesures morphométriques des femelles (masse, longueur du tarse et du bréchet). Le faible taux de survie quotidien des nids $(0,928, n=34$ nids) s'est traduit en un taux de succès de nidification prévu de 7,4\% pour une période d'exposition de 35 jours. Nous avons utilisé des modèles fondés sur le destin connu des individus afin de déterminer le taux de survie hebdomadaire à partir de données

${ }^{1}$ The Ohio State University at Lima, ${ }^{2}$ Kansas State University

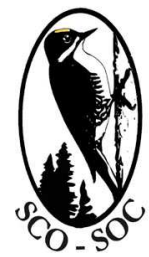

Sponsored by the Society of Canadian Ornithologists and Bird Studies Canada

Parrainée par la Société des ornithologistes du Canada et Études d'oiseaux Canada

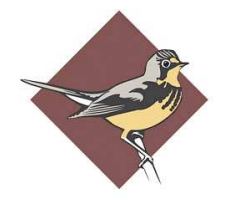


télémétriques provenant de 40 femelles. Le taux de survie hebdomadaire était de 0,970 et le taux de survie extrapolé pour l'ensemble des six mois de la saison de reproduction était de 45,7\%. À l'aide de modèles de Cormack-Jolly-Seber (temps depuis le marquage) applicables aux données de recapture pour tenir compte des individus en transit, le taux annuel de survie apparente de 55 femelles s'élevait à 0,277 $\pm 0,081$ (erreurtype) après leur capture initiale, et à $0,424 \pm 0,139$ pour les intervalles subséquents. Le taux de survie des femelles en dehors de la saison de reproduction était de 1,6 à 2 fois plus élevé que celui durant la saison de reproduction, probablement parce que les femelles sont davantage exposées à la prédation durant l'incubation et la période d'élevage des jeunes. La prédation des nids et des femelles représente peut-être le principal facteur démographique qui limite la viabilité des populations étant donné que la prédation - et non l'alimentation des femelles - était responsable du faible succès de reproduction et du faible taux de survie durant la reproduction des Tétras des prairies en milieu naturel. De futures recherches devraient examiner les pratiques d'aménagement des prairies qui permettent d'augmenter le couvert de nidification résiduel ou de réduire la prédation.

Key Words: female condition; Galliformes; life history trade-off; predation; reproduction; Tympanuchus cupido

\section{INTRODUCTION}

Habitat loss and fragmentation are among the primary factors leading to population declines in grassland birds (Brennan and Kuvlesky 2005). Eastern tallgrass prairie is one of the most highly altered biomes in North America (Ryan et al. 1998). With estimated losses of 82-99\%, the destruction of tallgrass prairie exceeds other major ecosystems in North America, including the bottomland hardwoods of south-central United States and the temperate rainforest of British Columbia (Samson and Knopf 1994). The historic range of Greater Prairie-Chickens (Tympanuchus cupido) extended from the prairie provinces of Canada south to central Texas and east to western Ohio (Schroeder and Robb 1993, Ross et al. 2006). However, prairiechickens have been extirpated or are vulnerable in 15 states and provinces (Schroeder and Robb 1993). Kansas is one of only four states with extant populations of $>5000$ breeding birds (Silvy et al. 2004, Ross et al. 2006). However, prairie-chickens have declined $\sim 70 \%$ in Kansas during the past 20 years (Applegate and Horak 1999, Svedarsky et al. 2000). Recent population declines in Kansas coincide with a shift in rangeland management of the tallgrass prairie from periodic burning and moderate cattle grazing, to annual burning and intensive early stocking of cattle at high densities for the first half of the growing season (Robbins et al. 2002). Development of energy resources, including oil and gas or wind power, may pose an additional risk if behavioral avoidance of anthropogenic features leads to habitat fragmentation (Pitman et al. 2005, Pruett et al. 2009). Based on their current status and threats, Greater PrairieChickens are listed as 'vulnerable' by the International Union for Conservation of Nature and Natural Resources (Birdlife International http://ww w.iucnredlist.org/apps/redlist/search).

Movement and demographic information are critical to determining the size of management units for the conservation of Greater Prairie-Chickens. Recent studies examining Greater Prairie-Chicken movements at the landscape scale were located in habitats that were only $15 \%$ grasslands (Ryan et al. 1998). Studies in more extensive, contiguous habitat are needed to serve as a reference for field studies of relict populations of prairie-chickens in marginal habitats. The Flint Hills of Kansas are largely unplowed prairie because of a rocky substrate and offer one of the best localities for studying prairiechicken ecology in contiguous habitats, but the most recent research on prairie grouse in this region was completed 25 years ago (Robel 1966, 1970, Robel and Ballard 1974, Horak 1985).

Nest and adult survival are important demographic parameters influencing the population dynamics of gamebirds (Wisdom and Mills 1997, Aldridge and Brigham 2001, Sandercock et al. 2005). In Greater Prairie-Chickens, nesting success ranges from $20-67 \%$ with considerable annual variation (Robel 1970, Schroeder and Robb 1993). Estimates of annual survival used in recent population models 
for Greater Prairie-Chickens (Wisdom and Mills 1997, Peterson et al. 1998) are based upon return rates collected $>30$ years ago from an isolated population in Wisconsin (Hamerstrom and Hamerstrom 1973). Contemporary estimates of juvenile and adult survival are needed in light of the ongoing population declines that have occurred in Kansas during the past 20 years (Applegate and Horak 1999). In addition to estimates of annual survival, seasonal estimates of breeding and nonbreeding survival are needed to determine the stage(s) of the annual cycle when birds are most vulnerable to population losses (Kirby and Cowardin 1986, Devries et al. 2003, Sandercock et al. 2008).

According to the 'predator-regulation hypothesis', predation may be the proximate factor mediating variation in nesting success and adult female survival. Predator numbers are inversely correlated with breeding success of Red Grouse (Lagopus lagopus scoticus) and Greater Sage-Grouse (Centrocercus urophasianus; Coates and Delehanty 2010, Fletcher et al. 2010), and predation is often the main cause of nest failure (Pitman et al. 2006). Predation by raptors or mammals also accounts for a majority of mortality of adult grouse (Schroeder and Baydack 2001, Warren and Baines 2002, Bowker et al. 2007).

Alternatively, demographic performance of grouse populations may be regulated by food availability and impacts of resource limitation on female condition. According to the 'maternal nutrition hypothesis', female condition is the main proximate factor mediating variation of nesting success and adult female survival (Moss et al. 1975). For example, egg size was related to female size in Greater Sage-Grouse (Atamian and Sedinger 2010). In a study of Black Grouse (Tetrao tetrix), clutch size correlated with female age, but not female condition (Rintamäki et al. 1998). Female condition may also relate to chick mass and adult survival, but this relationship may vary among habitats (Robb et al. 1992). More studies examining how female condition affects components of reproductive effort and survival are needed.

Conservation efforts would benefit from better information concerning the movements and demography of Greater Prairie-Chickens in contiguous, unfragmented grasslands in the core of their range (Applegate and Horak 1999, Peterson et al. 1998). Our objectives were to test the predation and maternal nutrition hypotheses by utilizing modern statistical techniques that control for variation in detection and exposure to estimate home range size, components of reproductive effort, and seasonal and annual demographic rates for female prairie-chickens. If predation is mediating variation in reproductive success (predatorregulation hypothesis), then we would expect to see negative impacts of predation on nesting success and female survival during the breeding season. If female condition determines the variation in reproductive success (maternal nutrition hypothesis), then phenotypic traits of females, including ageclass, mass, or tarsus length, should be correlated with laying date and components of reproductive effort, such as clutch size, egg size, nestling mass, or probability of renesting, and survival during the breeding season.

\section{METHODS}

\section{Study species}

Greater Prairie-Chickens are a resident species of grassland bird, and are unusual because they have a lek-mating social system. Males display in groups at lek sites which the females visit for the sole purpose of mating (Nooker and Sandercock 2008). Females alone construct the nest, incubate the eggs, and raise the precocial young to independence. One egg is laid per day until the clutch is completed, incubation lasts 23-25 days, and chicks leave the nest within 24-48 hours of hatching (Schroeder and Robb 1993). Chicks are capable of short distance flights by 2 weeks of age, but remain with their brood until about 80-84 days. In total, one reproductive attempt may last up to 120 days.

\section{Study site}

We monitored Greater Prairie-Chickens at four lek sites during mid-March and mid-May, 2003-2006. Leks were 0.8-6.2 km apart and consisted of 10-14 males per year. All leks were located on cattlegrazed pastures in Riley and Geary Counties in northeast Kansas, USA $\left(39^{\circ} 05^{\prime} \mathrm{N}, 96^{\circ} 34^{\prime} \mathrm{W}\right)$. Average temperature and precipitation in April was $14.8^{\circ} \mathrm{C}$ (range $13.7-17.3^{\circ} \mathrm{C}$ ) and $53.0 \mathrm{~mm}$ (range 17.0-89.7 mm), respectively (Konza Prairie Long Term Ecological Research Program 2004). We 
monitored three leks in 2003, and expanded our sampling effort to four leks in 2004-2006. Prairiechickens were captured and observed at lek sites during 2003-2005, and birds were resighted only in 2006 for estimation of apparent survival rates.

\section{Trapping and morphometrics}

Male and female prairie-chickens were trapped using walk-in funnel traps at lek sites and by spotlighting at night (Hamerstrom and Hamerstrom 1973, Schroeder and Braun 1991). When we discovered nests of unbanded females, the female was captured by placing a mist net over the nest during incubation. All birds were given a unique combination of colored leg bands for individual identification. Three morphometric measurements were recorded, including body mass ( $\pm 1 \mathrm{~g})$ and two linear measurements of body size (lengths of tarsus plus the longest toe, keel; $\pm 1 \mathrm{~mm}$ ). We determined age-class as second-year (SY) or after-second-year (ASY) from the shape, coloration and wear of the outermost two primaries (numbers 9 and 10; Schroeder and Robb 1993). A subset of males and females were fitted with necklace-style radio collars with an expected battery life of $\sim 18$ months and 24hour mortality sensors (Model RI-2BM, ca. $10.9 \mathrm{~g}$, Holohil Systems Ltd., Ontario, Canada; or Model TS - 25, ca. 15.6 g, Telemetry Solutions, Walnut Creek, California, USA).

\section{Estimation of home range size and distances}

Prairie-chicken locations were estimated weekly using two methods. We triangulated bird positions using hand-held Yagi antennas by recording the position of the observer and a compass bearing to the bird. We also approached birds on foot to locate nests and sites of mortality events. Handheld global positioning system receivers (GPS, Model III Plus, Garmin International Inc., Olathe, Kansas, USA) were used to record locations of triangulation points, bird sightings, and mortality events. Program Locate II was used to determine locations of radiomarked birds for each set of triangulation bearings ( $n=3$ or 4 bearings; Nams 2000, Millspaugh and Marzluff 2001). All locations were recorded in universal transverse mercator (UTM coordinates) and imported into ArcView for home range analyses (Ver. 3.3; Environmental Systems Research Institute, Inc., St. Charles, Missouri, USA).
Home range for the 6-month breeding season (March to August) was determined with three methods: minimum convex polygon (MCP) and $50 \%$ and $95 \%$ kernel estimates using the Animal Movement extension for ArcView (Hooge and Eichenlaub 2000). We used multiple methods for estimation of home range size to facilitate comparisons with published work. MCP requires less data for estimation but is more sensitive to outliers than kernel methods (Barg et al. 2005). The accuracy and precision of home range estimates are influenced by the number of locations. Biased estimates and large errors are associated with MCP estimates derived from $<10$ positions/individual and kernel estimates derived from $<15$ positions/ individual (Girard et al. 2002). Thus, calculation of MCP and maximum distance was restricted to birds with $>10$ positions recorded. For birds with $\geq 15$ positions, we also calculated $50 \%$ and $95 \%$ fixed kernel estimates. Lek and nest site locations were included once only in home range calculations for individual birds. Some authors recommend $>50$ locations for kernel estimates (Seaman and Powell 1996, Seaman et al. 1999), so our samples may not have been adequate. However, we include kernel estimates because they represent the most current data available on home range size of prairiechickens. In kernel metrics, the smoothing parameter was determined using the Least Square Cross Validation (LSCV) method (Seaman and Powell 1996, Gitzen and Millspaugh 2003). We used the $\chi^{2}$-approximation to the nonparametric Kruskal-Wallis test to examine sexual differences in home range size (JMP IN Ver. 4.0.4, SAS Institute, Cary, North Carolina, USA). Three additional linear measurements were determined in ArcView using the Animal Movement extension: the distance between the nest site and the lek of first capture, the distance between the nest site and the closest lek site, and the maximum distance traveled from the lek of first capture.

\section{Nest monitoring}

Radio-marked females were monitored until their movements became localized, and were flushed several days after settlement at a nest location to minimize disturbance during early egg-laying. Some nests were also found opportunistically when unmarked females were flushed from nests. Nest contents were examined by flushing females once or twice during incubation. We restricted our nest visits to hot, dry afternoons to minimize scent trails 
(Westemeier et al. 1998a). We recorded the position of the nest using handheld GPS receivers, marked the location using a flag placed $15-20 \mathrm{~m}$ from the nest in a random direction, and mapped nest locations relative to natural landmarks. We counted eggs to determine clutch size, and measured the maximum length $(L)$ and width $(W)$ of the eggs. Egg volume $(V)$ was calculated as $V=k L W^{2}$ where the shape coefficient $k$ was set at 0.49 for spherical eggs of grouse (Sandercock and Pedersen 1994). Eggs were also floated in a small cup of lukewarm water to estimate stage of incubation in the 24-day incubation period (Schroeder and Robb 1993, McNew et al. 2009). Buoyancy of eggs was related to stage of incubation as follows: horizontal on the bottom of the container $=0$ days; angle of $45^{\circ}=5$ days; vertical orientation $\left(90^{\circ}\right)=10$ days; floating at surface $=13$ days; $\sim 18 \mathrm{~mm}$ diameter circle protrudes above the water surface $=21$ days. On incubation days 22, 23, and 24, the initial stages of hatching were detected as faint tapping, star-shaped cracks in the egg shell, and small hole pips in the egg shell, respectively. Date of clutch initiation was estimated by back-dating from the stage of incubation and by assuming the laying period for a given clutch size was one egg per day. If lack of buoyancy indicated that incubation had not yet been initiated, we revisited the nest a week later to determine final clutch size and the start of incubation. If egg flotation indicated that incubation had been initiated (i.e., buoyancy $>30^{\circ}$ ), we considered egg-laying to have ended and the clutch to be complete.

Nests were monitored every other day by triangulating the female's radio signal at $>30 \mathrm{~m}$ from the nest site. If the female's signal was not heard from the nest location for two or three consecutive visits, the nest's contents were examined. Nests were visited daily at sunrise starting 1-2 days before the predicted day of hatching. Numbers of hatched and unhatched eggs were recorded. Nestlings were weighed $( \pm 0.1 \mathrm{~g})$ and measured (length of the tarsus, wing and total head from the back of the head to the tip of the beak, $\pm 1 \mathrm{~mm}$ ).

The nest survival procedure of Program Mark is a known fate model that allows estimation of daily nest survival rates while controlling for days of exposure, and can yield standardized estimates that are comparable among populations or management areas (Dinsmore et al. 2002, Rotella et al. 2004). The nest survival model improves upon Mayfield estimates (Mayfield 1975) because it relaxes the assumption of constant daily survival, is less sensitive to variation in nest monitoring efforts, and allows for daily survival rate to be modeled as a function of environmental covariates (Dinsmore et al. 2002). The daily probability of nest survival $(S)$ was estimated using the nest survival procedure in Program Mark (Ver. 4.1; White and Burnham 1999, Dinsmore et al. 2002, Rotella et al. 2004). Five assumptions of the nest survival model were met: stage of egg laying or incubation was correctly determined when they are first found, nest fates were correctly determined, discovery and subsequent check did not influence nest survival, nest fates were independent, and daily nest survival rates were homogeneous (Nooker 2007). We modeled the effect of nest age on daily survival rate using nest survival analyses in Program Mark (Cooch and White 2009). We included estimated age of nest at discovery as an individual covariate. We set the earliest date the first nest was found ( 22 April = 1) and calculated $k$ (date nest was found), $l$ (last date nest was checked and was active) and $m$ (last date nest was checked; if successful, $l=m$; if unsuccessful, $l \neq m$ ) relative to that date for all nests. Daily probability of survival was modeled as a constant $(c)$, as a linear function of day of season (lin), age of the nest (age), and in models with maineffects $(+)$ only or with interactions among these factors $(\times)$.

\section{Breeding survival of females}

To measure seasonal survival during the 6-month breeding period, we monitored the subset of females that received radio collars, and modeled weekly probability of female survival $(S)$ using the nest survival procedure in Program Mark. Originally developed for nest data, this procedure can also be applied to 'ragged' telemetry data for radio-marked birds (Hartke et al. 2006, Mong and Sandercock 2007). Birds that were never detected after first marking and presumably had failed radios were censored from analysis ( $n=7$ females). We assume that our censoring was random, noninformative, and had limited effect on our survival estimates (Murray 2006), which was the case for a similar field study of Lesser Prairie-Chickens (T. pallidicinctus; Hagen et al. 2006). To test the sensitivity of our results to the assumption that censoring was random, we developed two models. The first model coded females that were not detected greater than two 
weeks into the study as 'surviving'. A second model coded these females as 'dead'. Weekly probability of survival was modeled as a function of mass at initial capture (mass), week since marking $(t)$, a linear trend throughout the season (lin), a quadratic trend throughout the season (quad), constant (c), and additive $(+)$ combinations of these factors.

Causes of mortality were grouped into four categories based on the following criteria (Hagen et al. 2007, Wolfe et al. 2007). We discuss 'probable causes of mortality' because it is difficult to make unambiguous statements about causes of mortality if scavenging can occur (Bumann and Stauffer 2002). Cases where feathers, radios, or leg bands were chewed, had obvious tooth marks, and were clumped in a small area $\left(\sim 1 \mathrm{~m}^{2}\right)$ were considered to be probable mammalian predation. Cases where feathers were cut and spread over $2 \mathrm{~m}$ were considered probable raptor predation. Cases where the carcass was intact, was located near the nest and had feathers that were pasted to the body were considered to be probable snake predation and a failed attempt to ingest the carcass. Birds found dead on roadsides or near fences with evidence of traumatic injuries were considered collision mortalities. We visited mortality locations as soon as a mortality signal was detected, but it is possible that some carcasses were scavenged before we located the remains.

\section{Annual survival of females}

To obtain resightings of females for use in estimation of annual survival, we observed birds at leks during early mornings from a blind placed $\sim 6$ $\mathrm{m}$ from the edge of each lek (Nooker and Sandercock 2008). Between mid-March through early May, leks were observed every 1-2 days to record visits and the identity of color-banded and radio-marked females. We estimated apparent survival of females using time-since-marking Cormack-Jolly-Seber (CJS) models for live encounter data in Program Mark (Ver. 4.1; White and Burnham 1999). CJS models based on live encounter data improve upon return rates by separating apparent survival $(\Phi)$ from the probability of encounter ( $p$; Sandercock 2006). Annual survival $(\Phi)$ was modeled as a function of time $(t)$ or constant $(c)$; we also used a time-sincemarking model to estimate annual survival separately in the transition after initial capture $\left(\Phi^{1}\right)$ from subsequent intervals $\left(\Phi^{2+}\right)$ to determine if transience affected apparent survival. Resighting probability $(p)$ was modeled as a function of time $(t)$ or held constant $(c)$. We were unable to test whether transmitters affected survival of female prairie-chickens because of small sample sizes, but necklace transmitters have no impact on survival rates of female Lesser Prairie-Chickens (Hagen et al. 2006). Our global model for the mark-resight data was: $\Phi^{1}{ }_{t}, \Phi^{2+}{ }_{t}, p_{t}$. A variance inflation factor (c) was estimated to control for potential lack of fit and was estimated using bootstrap goodness-of-fit (GOF) tests using 1000 replicates on the global model (White et al. 2001).

\section{Synthetic estimates}

Prairie-chicken nests were discovered at different stages of the nesting cycle. To obtain an unbiased estimate of fecundity per nest $\left(F_{n}\right)$ that controlled for variation in nest exposure and made full use of our demographic parameters, we calculated the mean number of female chicks produced per female by:

$$
\begin{aligned}
F_{n}= & \left\{\left[\mathrm{BREED} \times \mathrm{TCL}_{1} \times \mathrm{HATCH}_{1}\right]+\left[\left(1-\mathrm{HATCH}_{1}\right)\right.\right. \\
& \left.\left.\times \mathrm{RENEST} \times \mathrm{TCL}_{2} \times \mathrm{HATCH}_{2}\right]\right\} \times \mathrm{ES} \times \mathrm{HS} \times 0.5
\end{aligned}
$$

where BREED = probability of breeding, TCL = total clutch laid, HATCH = probability of a nest hatching at least one chick, RENEST = probability of renesting after clutch loss, ES = proportion of eggs that survived until hatching if the nest survived incubation, $\mathrm{HS}=$ proportion of eggs hatching if the nest survived incubation, subscripts 1 and 2 indicating estimates for first and second nests, and 0.5 is the assumed sex ratio of females per clutch. Values of HATCH, ES, and HS $<1$ were due to total nest loss, partial nest loss, and egg inviability, respectively. HATCH was calculated as the product of estimates from the best fit nest survival model from the average laying date of first and second nests for 35 days or 24 days. Thirty-five days corresponds to the combined length of the average duration of the stages of egg-laying (11 days, see Results) and incubation (24 days; Schroeder and Robb 1993); 24 days is the duration of incubation alone and would be the period of exposure if predation is negligible during egg laying.

To estimate juvenile survival $\left(S_{j u v}\right)$ from hatching until the spring of the following year necessary for a stationary population, we used the equation: 


$$
S_{j m}=\frac{\lambda-S_{f m}}{F_{n}}
$$

where $\lambda$ is the finite rate of population change and equals 1 for a stationary population, $F_{n}$ was the seasonal estimate of fecundity per female, and $S_{f e m}$ was maximum annual apparent female survival as estimated from the Cormack-Jolly-Seber markresight models $\left(\Phi^{2+}\right)$. This value for $S_{f e m}$ was chosen because it is likely closer to the true estimate for survival than survival after initial capture $\left(\Phi^{1}\right)$, which may include transient individuals. To obtain estimates of the variance of our synthetic estimates of fecundity, we used parametric bootstrapping in Program R (Ver. 2.11.1, R Foundation for Statistical Computing, www.R-project.org). Total clutch laid was modeled as draws from a normal distribution (rnorm function), and all probabilities were modeled as draws from beta distribution (betaval function of the popbio package). We took a random draw for each demographic parameter, combined them to estimate $F_{n}$, and then repeated the steps for 10,000 bootstrap iterations. The variance of $F_{n}$ was then taken directly from the bootstrap distribution, and the $95 \%$ confidence intervals were taken as the $2.5 \%$ and $97.5 \%$ quantiles.

\section{Statistical analyses}

Components of fecundity were analyzed using procedures of Program JMP IN (Ver. 4.0.4, SAS Institute, Cary, North Carolina, USA). Correlates of laying date, clutch size, egg volume, and nestling size were analyzed using one-way Analysis of Variance (ANOVA). Egg volume and nestling measurements were averaged per female before analysis because eggs and nestlings within a clutch were not independent observations. Mass and size were not related (tarsus: $r^{2}=0.015, F_{127}=0.42, P$ $=0.52 ;$ keel: $\left.r^{2}=0.012, F_{1,27}=03.71, P=0.06\right)$, so mass, tarsus, and keel were considered separate independent variables in the analyses. Sample sizes varied among analyses because it was not possible to measure every parameter for all birds.

Models of apparent survival in Program Mark were constructed with design matrices and the logit link function. The number of parameters was adjusted to match the model structure, which in most cases was the number of columns in the design matrix. Model selection was based on the information theoretic approach, and we considered the model with the lowest Akaike's Information Criterion value corrected for small sample sizes (AICc) to be the best supported by the data (Burnham and Anderson 2002). Models with $\triangle \mathrm{AICc} \leq 2$ were considered equally parsimonious. When two or more models were similarly parsimonious, we used the model averaging procedure in Program Mark to obtain overall parameter estimates (Burnham and Anderson 2002, Cooch and White 2009). Akaike weights $\left(w_{i}\right)$, model-averaged estimates, $\hat{\theta}_{a}$ and weighted unconditional standard error $[\mathrm{SE}] \hat{\theta}_{a}$ were calculated using formulae in Burnham and Anderson (2002; eqns. 4.1 and 4.9). Variance of extrapolated estimates was calculated using the delta method (Powell 2007). Descriptive statistics are presented as mean $\pm 1 \mathrm{SE}$.

\section{RESULTS}

In the 3-year period of 2003-2005, we captured, banded and fitted 43 female and 4 male prairiechickens with necklace radio collars in northeast Kansas. An additional 15 females were banded only. Necklace radios (11-16 g) were 1.2 to $1.8 \%$ of female body mass at capture $(889 \pm 13 \mathrm{~g} ; n=32)$ and 1.1 to $1.5 \%$ of male body mass $(1,007 \pm 31 \mathrm{~g}$; $n=4)$.

\section{Home range size}

Females moved a maximum distance of $3.7 \pm 0.7$ $\mathrm{km}$ from the lek where they were first banded $(n=$ 8 females with $\geq 10$ locations) and had minimum convex polygon (MCP) estimates of home ranges $395 \pm 78$ ha in size (range: 130 to 804 ha; $n=9$ females). MCP estimates of home ranges for males were $153 \pm 87$ ha (range: 51 to $327 \mathrm{ha} ; n=3$ ), and were similar in size to MCP estimates of home ranges for females $(Z=-1.47, P=0.14)$. For females, $95 \%$ kernel estimates of $575 \pm 65$ ha (range: 469 to 831 ha; $n=5$ ) were $39.2 \%$ larger than the MCP estimates. The core use areas based on 50\% kernel estimates were $95 \pm 16$ ha (range: 66 to $155 \mathrm{ha}$ ), which was $16.6 \%$ of the $95 \%$ kernel estimate $(n=5)$.

\section{Nesting propensity}

Of 24 females fitted with radio collars before egg laying and where three or more locations were obtained, nests were located for 19 females $(79.2 \%)$. Two females presumably initiated nests because of localization of their movements and broody 
behavior, such as flying short distances when approached and emitting clucking calls $(8.3 \%)$, but their nests were never located. The remaining three birds dropped their radios shortly after marking and before nests could be located (12.5\%). Thus, the probability of nesting (BREED) was estimated as 1.0 for female prairie-chickens.

During 2003-2005, 34 nests were found for 24 radiomarked females and one unmarked female. One nest was depredated before the female could be captured and marked. Following nest failure, $22.2 \%$ of females laid a second nest (RENEST, $n=27$ females). Females tended to be more likely to attempt second nests if first nests were destroyed during egg laying or early incubation $\left(\chi_{2,18}^{2}=2.69\right.$, $P=0.10$; Figure 1), but probability of renesting was not affected by the seasonal timing of loss $\left(\chi^{2}{ }_{2,18}=\right.$ $0.12, P=0.73$; overall logistic model $\chi_{2,18}^{2}=3.42$, $P=0.18)$.

\section{Laying date}

Average date of clutch initiation for first nests was 5 May \pm 3 days (range $=14$ April to 3 June; $n=27$ ). Laying date of first clutches did not correlate with female age-class, mass at capture, or linear measurements of tarsus or keel (all $P>0.11$; model $F_{5,18}=1.18, P=0.36$ ). Average date of clutch initiation for known renesting attempts was 24 May \pm 5 days (range $=4$ May to 9 June; $n=6$ ).

\section{Clutch size}

Average clutch size of first nests was $10.9 \pm 0.3$ eggs $\left(\mathrm{TCL}_{1}\right.$, range $=7$ to 14 eggs; $\left.n=24\right)$ and did not vary with respect to laying date, female age-class, mass, tarsus, or keel (all $F$ ratio $<2.29, P>0.15$; model $\left.F_{6,14}=1.18, P=0.12\right)$. Average clutch size of renesting attempts was $10.8 \pm 1.0$ eggs $\left(\mathrm{TCL}_{2}\right.$, range 8 to $15 ; n=6)$, and was not different from the clutch size of first nesting attempts $\left(F_{1,28}=0.01, P\right.$ $=0.92$ ).

\section{Egg measurements}

Average egg length and width were $42.4 \pm 0.2 \mathrm{~mm}$ and $31.7 \pm 0.1 \mathrm{~mm}$, respectively ( $n=32$ clutches). Average egg volume per female was $20.8 \pm 0.2 \mathrm{~cm}^{3}$ $(n=32$ clutches). Egg volume tended to increase with increasing tarsus length of females $(F$ ratio $=$
3.66, $P=0.07)$, but egg volume did not vary with respect to laying date, clutch size, female mass, female keel length, or female age-class (all $F$ ratios $<1.26, P>0.31$; overall model: $F_{7,18}=0.77, P=$ $0.62)$.

\section{Nesting success}

Apparent nesting success was higher for renesting attempts $(66 \%, 4$ of 6 nests successful) than first nests $(11 \%, 3$ of 28 nests successful; Fisher's exact test $P=0.01)$. Pooling first and second nesting attempts, apparent nesting success was low $(20.6 \%$; $n=34$ ). Of 27 nests that failed to hatch, $85.2 \%$ of nests were depredated, $11.1 \%$ were destroyed by prescribed fires, and $3.7 \%$ were abandoned. In addition, the female attending the nest was found dead beside the depredated nest in 3 of 27 failed nesting attempts $(11 \%)$. Probable causes of female mortality during incubation included snakes $(n=1)$ and mammals $(n=2)$. Of nests that survived until hatching, two clutches were partially depredated during incubation, and overall $75.6 \pm 13.2 \%$ of eggs laid per clutch survived the incubation period until hatching (ES, $n=7$ nests). Among eggs in nests surviving to hatching, egg hatchability was high and $89.3 \pm 4.7 \%$ of eggs produced chicks (HS, $n=7$ nests).

Daily nest survival was modeled using data from 34 nests of Greater Prairie-Chickens, over an 84-day nesting period (22 April to 14 July). The best fit model included a linear effect of time on nest survival (Table 1). Model-averaged estimates revealed that daily nest survival increased throughout the nesting season from $0.868 \pm 0.069$ during the first week (22 April) to $0.958 \pm 0.023$ during the last week (15 July). Nest age had a positive, but nonsignificant effect on nest survival (Table $1 ; \beta=0.02 \pm 0.01 ; 95 \%$ CI: -0.005 to 0.04 ). Using a constant model, daily nest survival throughout the entire season was $0.928 \pm 0.013$ (95\% CI: 0.897 to 0.951 ). On average, we found nests when they had been incubated four days, so our expected apparent survival of $22.6 \pm 6.5 \%$ $\left(0.928^{20}\right)$ was close to our observed apparent survival of $20.6 \%$. Assuming a 24-day incubation period, an average clutch size of 11 eggs, and constant risk of predation during laying and incubation, nest success was extrapolated to be 7.4 $\pm 3.7 \%\left(0.928^{35}\right)$. Since we found most nests after the female initiated incubation, females may visit nests for short periods each day during egg-laying. 
Fig. 1. Probability of renesting as a function of the stage of development of the first nesting attempt when the nest was destroyed. First nests of 23 females were destroyed by natural causes at prairie sites in northeast Kansas, 2003-2005. Points on the $\mathrm{x}$-axes represent females which renested $(\mathrm{y}=1)$ or did not attempt renesting $(\mathrm{y}=0)$. Nests with negative values for day of incubation were destroyed during egg laying.

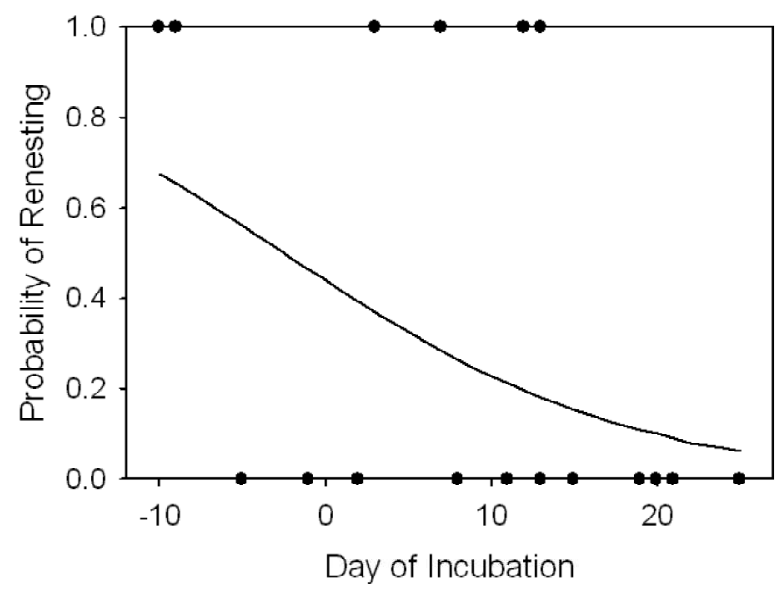

Thus, the risk of nest predation may be lower during laying than incubation if female attendance increases risk of detection by a predator. Under this scenario, if predation exposure is limited to the incubation period, a maximum estimate of nest survival was $16.8 \pm 5.8 \%\left(0.928^{24}\right)$ for first nests and renesting attempts combined. Using daily survival rates from the best fit model that included a seasonal increase in daily survival rates, the proportion of nests surviving until hatching was $0.041 \pm 0.006$ for first nests $\left(\mathrm{HATCH}_{1}\right)$ and 0.117 \pm 0.01 for renesting attempts $\left(\mathrm{HATCH}_{2}\right)$ for a 35day exposure period. For a 24-day exposure period, the proportion of nests surviving until hatching could be higher, and $0.088 \pm 0.01$ for first nests $\left(\mathrm{HATCH}_{1}\right)$ and $0.196 \pm 0.02$ for renesting attempts $\left(\mathrm{HATCH}_{2}\right)$.

\section{Nestling measurements}

Average total head length of hatchlings was 28.0 $\pm 0.2 \mathrm{~mm}$ ( $n=7$ broods $)$ and was correlated with female mass $(\beta=0.01 \pm 0.001, P<0.01)$ and tarsus length $(\beta=-0.11 \pm 0.02, P=0.02)$, but not mean egg volume $\left(\beta=0.18 \pm 0.19, P=0.43 ; \operatorname{model} F_{3,3}=\right.$ $36.5, P=0.01)$. Average nestling tarsus, wing and mass were $18.6 \pm 0.1 \mathrm{~mm}, 18.9 \pm 0.5 \mathrm{~mm}$, and 15.6 $\pm 0.5 \mathrm{~g}$, respectively ( $n=7$ broods). None of these measurements varied with female mass $(P>0.12)$, female tarsus length $(P>0.30)$, or mean egg volume $\left(P>0.11\right.$; model $\left.F_{3,3}<1.74, P>0.33\right)$.

\section{Breeding survival of females}

Of 43 females fitted with radio collars, seven females were never detected after capture and were censored from the analysis of breeding season survival. Four females were monitored in years subsequent to the year of banding and were included twice in our analyses of breeding season survival. Of the 40 females included in the survival analysis, seven were alive at the end of the breeding season $(17.5 \%)$, six dropped their radio collars and were considered alive at last observation $(15.0 \%), 10$ were recovered as dead birds $(25.0 \%)$, and 17 were not detected $>2$ weeks into the study $(42.5 \%)$. Of the 10 females found dead, probable cause of mortality included four killed by mammals, two by raptors, two by collisions with a fence or vehicle, one by a snake, and one mortality of unknown cause. Hunting pressure on prairie-chickens in our study area was minimal, and we received no reports of bands recovered from birds killed by hunters.

The best fit model to the telemetry data for females was the constant model $\left(S_{\mathrm{c}}\right)$, regardless of whether females that were not detected $>2$ weeks into the 
Table 1. Comparison of nest survival models examining the survival of nests of Greater Prairie-Chickens (Tympanuchus cupido) in northeast Kansas between 2003 to $2005(n=34)$. Table abbreviations are as follows: $S$ = parameters included in the survival model; $\mathrm{Dev}=$ deviance; $K=$ number of parameters; AICc $=$ Akaike's Information Criterion corrected for small sample sizes; $\Delta \mathrm{AICc}=$ difference of the AICc value in the given model compared to the minimum AICc model; and $w_{i}=$ Akaike weights. Model factors are as follows: $\operatorname{lin}=$ linear time; age $=$ nest age; $c=$ constant $\times=$ interaction; and $+=$ main effects model.

\begin{tabular}{lcccccc}
\hline \hline Model & $S$ & Dev & $K$ & AICc & $\Delta$ AICc & $w_{i}$ \\
\hline 1 & lin & 139.5 & 2 & 143.5 & 0.00 & 0.35 \\
2 & age & 140.1 & 2 & 144.2 & 0.64 & 0.25 \\
3 & $c$ & 142.6 & 1 & 144.6 & 1.04 & 0.21 \\
4 & 139.4 & 3 & 145.5 & 1.95 & 0.13 \\
5 & lin+age & 4 & 147.3 & 3.82 & 0.05 \\
\hline
\end{tabular}

study were considered alive or dead (Table 2). If females that were not detected were considered alive, weekly apparent survival estimates were $0.970 \pm 0.009$ (95\% CI: 0.946 to 0.984$)$. If this estimate is extrapolated, apparent survival would be $45.3 \pm 11.4 \%\left(0.970^{26}\right)$ for the 6-month (26-week) breeding season from March to August. There was support for models that included an effect of mass and a linear trend $(\triangle \mathrm{AIC}<2.0$; Table 2$)$. Female mass at capture had a positive, but nonsignificant effect on female survival $(\beta=0.27 \pm 0.32 ; 95 \%$ CI: -0.36 to 0.90$)$. Female survival declined linearly throughout the breeding season (week $1=0.978$ \pm 0.013 ; week $23=0.955 \pm 0.032$ ).

If females that were not detected $>2$ weeks into the study were considered dead, weekly survival estimates were reduced to $0.922 \pm 0.014$ (95\% CI: 0.889 to 0.946 ). If this estimate is extrapolated, survival would be $12.2 \pm 4.9 \%$ for the 26 -week breeding season $\left(0.922^{26}\right)$. Models that included linear or quadratic time trends were supported, along with an effect of mass $(\triangle \mathrm{AIC} \leq 2.01$; Table 2 ), but the trends were not in the same direction as when undetected females were considered alive.

A linear model indicated that female survival increased slightly during the breeding season (week $1=0.920 \pm 0.026$; week $23=0.925 \pm 0.037$ ). The quadratic time trend showed a midseason decrease in survival which fell to $0.893 \pm 0.027$ while females were incubating nests, with higher estimates during prelaying and brood-rearing periods at the beginning and end of the breeding season $(0.980$ $\pm 0.023)$. Contrary to predictions of the maternal nutrition hypothesis, female mass had a negative, but nonsignificant effect on female survival $(\beta$ $=-0.10 \pm 0.23 ; 95 \%$ CI: -0.55 to 0.35$)$.

\section{Annual survival of females}

Fifty-five females were banded between 2003 and 2005 , and 13 birds were resighted in subsequent years. One female was observed every year during the entire 4-year study period. There was no evidence for overdispersion using bootstrap goodness-of-fit procedures (mean expected $\mathrm{c}$-hat $=$ $0.35 ; P=0.74)$. Thus, we set the variance inflation factor to 1 and used AICc for model selection. The best fit model for apparent survival included a timesince-marking effect that separated the interval following initial capture from subsequent intervals, and a constant resighting probability $\left(\Phi^{1}{ }_{t}, \Phi^{2+}{ }_{t}, p_{c}\right.$; Table 3). Model-averaged estimates showed considerable variation among years. Apparent survival of females after first capture was 0.277 \pm 0.081 (range: 0.180 to 0.341 ) and in subsequent intervals was $0.424 \pm 0.139$ (range: 0.355 to 0.430 ). Overall estimates of apparent survival of females regardless of time since capture was $0.328 \pm 0.083$ (95\% CI: 0.189 - 0.506). Model-averaged estimates 
Table 2. Comparison of nest survival models examining the survival of radio-marked females during the breeding season $(n=40$ females). Females included in the analysis were marked at three Greater PrairieChicken (Tympanuchus cupido) leks between 2003 to 2005 in northeast Kansas and were detected two weeks after banding. Seventeen birds were not detected during the period two weeks after banding and the end of the breeding season (1 September). Two data sets were analyzed: one assuming these missing birds were alive at the end of the study and the other assuming these birds were dead. Table abbreviations are as follows: $S=$ parameters included in the survival model; $\mathrm{Dev}=$ deviance; $K=$ number of parameters; $\mathrm{AICc}=$ Akaike's Information Criterion corrected for small sample sizes; $\triangle \mathrm{AICc}=$ difference of the AICc value in the given model compared to the minimum AICc model; and $w_{i}=$ Akaike weights. Model factors are as follows: $t=$ time; mass $=$ mass at initial capture; lin = linear seasonal trend; quad = quadratic seasonal trend; $c=$ constant; and $+=$ additive model.

\begin{tabular}{|c|c|c|c|c|c|c|}
\hline Model & $S$ & Dev & $K$ & AICc & $\Delta \mathrm{AICc}$ & $w_{i}$ \\
\hline \multicolumn{7}{|c|}{ Assuming birds that were not detected to have survived } \\
\hline 1 & $c$ & 83.1 & 1 & 85.1 & 0.00 & 0.43 \\
\hline 2 & mass & 82.4 & 2 & 86.5 & 1.35 & 0.22 \\
\hline 3 & $\operatorname{lin}$ & 82.7 & 2 & 86.8 & 1.67 & 0.19 \\
\hline 4 & quad & 81.7 & 3 & 87.8 & 2.72 & 0.11 \\
\hline 5 & quad + mass & 81.4 & 4 & 89.5 & 4.39 & 0.05 \\
\hline 6 & $t$ & 69.5 & 23 & 119.1 & 34.01 & 0.00 \\
\hline \multicolumn{7}{|c|}{ Assuming birds that were not detected to have died } \\
\hline 1 & $c$ & 182.9 & 1 & 184.9 & 0.00 & 0.40 \\
\hline 2 & quad & 180.0 & 3 & 186.1 & 1.23 & 0.21 \\
\hline 3 & mass & 182.7 & 2 & 186.7 & 1.83 & 0.16 \\
\hline 4 & $\operatorname{lin}$ & 182.9 & 2 & 187.9 & 2.01 & 0.15 \\
\hline 5 & quad + mass & 179.9 & 4 & 188.0 & 3.15 & 0.08 \\
\hline 6 & $t$ & 153.7 & 23 & 203.2 & 18.31 & 0.00 \\
\hline
\end{tabular}

of resighting probability were constant during the study at $0.857 \pm 0.174$ (95\% CI: $0.270-0.990)$.

\section{Nonbreeding survival of females}

We calculated survival during the 6-month nonbreeding season (mid-September to midMarch) by combining our estimates of annual survival and seasonal estimates of survival for the 6-month breeding season (mid-March through midSeptember). Annual survival was 0.424 among females that showed site-fidelity and breeding season survival was 0.453 for radio-marked females (assuming females not detected $>2$ weeks into the study were considered alive), so survival during the 6-month nonbreeding season might be as high as $0.424 / 0.453=0.936$. If so, survival of females during the nonbreeding season might be 2.1 times 
Table 3. Comparison of Cormack-Jolly-Seber mark-resight models examining the apparent survival of individually marked females between breeding seasons $(n=55$ females). Females were marked and observed at four Greater Prairie-Chicken (Tympanuchus cupido) leks during a 4-year period in northeast Kansas, 2003 to 2006. Table abbreviations are as follows: $\Phi^{1}=$ apparent survival for females after initial capture; $\Phi^{2+}=$ apparent survival of females in subsequent intervals; $p=$ probability of encounter; Dev = deviance; $K=$ number of parameters; AICc $=$ Akaike's Information Criterion corrected for small sample sizes; $\Delta$ AICc $=$ difference of the AICc value in the given model compared to the minimum AICc model; and $w_{i}=$ Akaike weights. Model factors include: $t=$ year and $c=$ constant. Separate abbreviations for $\Phi^{1}$ and $\Phi^{2+}$ indicates a time-since-marking model; whereas, an abbreviation between $\Phi^{1}$ and $\Phi^{2+}$ indicates that the two classes were not modeled separately.

\begin{tabular}{llllllllll}
\hline \hline Model & $\Phi^{1}$ & & $\Phi^{2+}$ & $p$ & Dev & $K$ & AICc & $\Delta$ AICc & $w_{i}$ \\
\hline 1 & $t$ & & $t$ & $c$ & 1.6 & 6 & 90.2 & 0.00 & 0.28 \\
2 & & $c$ & & $c$ & 11.0 & 2 & 90.4 & 0.19 & 0.25 \\
3 & & $t$ & & $c$ & 10.1 & 3 & 91.7 & 1.53 & 0.13 \\
4 & $t$ & & $t$ & $t$ & 0.7 & 7 & 91.8 & 1.57 & 0.13 \\
5 & & $c$ & & $t$ & 8.9 & 4 & 92.8 & 2.59 & 0.08 \\
6 & & $t$ & & $t$ & 6.8 & 5 & 93.0 & 2.83 & 0.07 \\
7 & & & $c$ & $c$ & 10.0 & 4 & 93.9 & 3.71 & 0.04 \\
8 & $c$ & & $c$ & $t$ & 8.0 & 5 & 94.3 & 4.06 & 0.04 \\
\hline
\end{tabular}

higher than during the breeding season. If we used our overall estimate of annual survival of females (0.328), a conservative estimate of survival during the 6-month nonbreeding season would be $0.328 / 0.453=0.724$. In this case, nonbreeding survival of females might be 1.6 times higher than survival during the breeding season.

\section{Synthetic estimates}

Our unbiased estimate of fecundity per nest $\left(F_{n}\right)$ controlled for variation in nest exposure, and was $0.24 \pm 0.05(95 \% \mathrm{CI}=0.14-0.34)$ and $0.47 \pm 0.01$ $(95 \% \mathrm{CI}=0.27-0.66)$ female chicks per female using estimates of nest survival based on 35 and 24 day exposure periods, respectively. To attain a stationary rate of population change $(\lambda=1)$ with fecundity $\left(F_{n}\right)=0.47$ and annual female survival $\left(S_{f e m}\right)=0.424$, juvenile survival $\left(S_{j u v}\right)$ would have to be $>1 . S_{j u v}$ is more likely to be 0.124 based on a published estimate from a field study of Lesser Prairie-Chickens (Pitman et al. 2006). Using this value for juvenile survival, the finite rate of population growth would be 0.45 or 0.48 using $F_{n}$ values of 0.24 and 0.47 , respectively. Predicted $\lambda^{n}$ values $<<1$ indicate steep declines in population size in the absence of immigration. To maintain a stationary population given our field estimates of juvenile and adult survival, fecundity per nest would have to be increased from 0.47 to $>4.6$ female chicks per female, a rate equivalent to a nest survival rate of 1.0 because clutch size averages 11 eggs. Thus, both fecundity and female survival rates are apparently depressed in prairie-chicken populations breeding in contiguous prairie in northeast Kansas. 


\section{DISCUSSION}

Our data provide support for the predator-regulation hypothesis because Greater Prairie-Chickens breeding in natural, unfragmented grasslands experienced high rates of predation on nests and incubating females, thereby limiting the finite rate of population change. Contrary to the predictions of the maternal nutrition hypothesis, we could not detect any relationships between female traits (mass, size) and laying date, clutch size, egg volume, nestling mass, or breeding season survival. A lack of an effect of female body condition on components of reproductive effort was contrary to analyses for other grouse species (Moss et al. 1975, 1981, Robb et al. 1992). Our estimates of components of reproduction were similar to published estimates of clutch size (10.7 eggs, Horak 1985; 10.9, this study; 11.3, Schroeder and Robb 1993; 11.6, Robel 1970; 12.0, Hamerstrom 1939; 12.1, Peterson and Silvy 1996) and egg hatchability (86-93\%, Lutz et al. 1994; 89\%, Peterson and Silvy $1996 ; 89 \%$, this study; $91 \%$, Lockwood et al. 2005; $98 \%$, Hamerstrom 1939). Additional research may find support for the maternal nutrition hypothesis by examining additional components of reproduction that were beyond the scope of this study, such as yolk mass or juvenile survival. We may have failed to detect a relationship between female traits and their eggs or offspring because predation risk, climatic conditions, and other environmental factors have a greater impact on grouse survival and reproduction than individual variation among females (Dusek et al. 2002).

If nesting success is the main demographic parameter limiting prairie-chicken numbers (Wisdom and Mills 1997, Hagen et al. 2009), it is important to have contemporary estimates to guide management decisions. Our estimates of the probability a female will initiate nesting $(100 \%)$ was high and consistent with previous studies (90-100\%; Wisdom and Mills 1997). However, our apparent nesting success $(20.6 \%)$ was considerably lower than other reported rates $(26 \%$, Robel $1970 ; 30 \%$, Horak 1985; 48\%, Hamerstrom 1939; 50\%, Peterson and Silvy 1996) including those for the endangered subspecies of Greater Prairie-Chicken (Attwater's Prairie-Chicken T. c. attwateri; 39\%, Lockwood et al. 2005). Observed rates of nesting success are biased high because they do not control for nests destroyed by predators before discovery by an observer. Our estimate of apparent nest survival might be lower than past estimates of nest survival because we used radio-telemetry to track females and located nests early in the nesting cycle (Green 1989). We report one of the first applications of nest survival models to estimation of Greater Prairie-Chicken nesting success. Our estimate of daily survival of 0.928 controls for varying exposure and facilitates direct comparisons among studies. Nest survival increased during the breeding season, possibly because prescribed burning was usually conducted early in the breeding season in March and April and vegetative growth leads to increased nesting cover later in the breeding season. If our estimate for daily nest survival is extrapolated to include both the egg-laying and the entire incubation period, estimated nesting success would be $7.4 \%$. This value is considerably lower than apparent rates of nesting success. Future management experiments in contiguous prairie could include predator removal or changes in rangeland management to increase nesting cover (Schroeder and Robb 1993, Schroeder and Baydack 2001).

High nest failure may be why we observed higher rates of renesting $(22.2 \%)$ than previous studies (0-17\%; Wisdom and Mills 1997, Lockwood et al. 2005). Higher rates of renesting mitigated the effect of prescribed fires on nest survival, but females moved long distances to locate unburned areas with suitable nesting cover for renesting attempts. Ringnecked Pheasants (Phasianus colchicus) were observed in the study area infrequently, but we found no evidence of interspecific nest parasitism with pheasant eggs in nests of prairie-chickens (Westemeier et al. 1998b). The probability of renesting varied with the timing of nest loss, and females were more likely to renest if their first nest was destroyed during laying or early incubation similar to Willow Ptarmigan (Lagopus lagopus; Robb et al. 1992). Contrary to McNew et al. (2011), we did not detect seasonal declines in the probability of renesting. In the Flint Hills of Kansas, annual burning of prairie is a conventional rangeland management technique to promote grass forage for cattle and to reduce woody vegetation. Prescribed fires conducted less frequently or in other seasons of the year would reduce direct losses of prairie chicken nests, with added benefits for regional air quality. If prescribed fires are conducted in midApril before the growing season, females that lose nests from fires should have a higher rate of renesting, but still have adequate time to produce broods from replacement clutches. 
Our seasonal estimates of survival indicated that female Greater Prairie-Chickens are most vulnerable during the breeding season, consistent with previous results for Lesser Prairie-Chickens (Hagen et al. 2007). Females can suffer high mortality while attending nests during incubation (9.2\%, Hamerstrom $1939 ; 11.1 \%$, this study), and seasonal survival during the 6-month breeding season was $45.7 \%$ using known fate models. Breeding season survival of our population of Greater Prairie-Chickens is somewhat higher than estimates for the endangered subspecies, Attwater's Prairie-Chicken (36\%, Lutz et al. 1994). Evidence at mortality sites indicated that predation was the main proximate factor reducing seasonal survival of nesting females in both Lesser and Greater Prairie-Chickens (Hagen et al. 2007; this study). Although predation was the main cause of mortality, it is possible that other proximate factors, such as parasite loads and nutritional stress may reduce survival by increasing susceptibility to predation risk (Hannon and Martin 2006). Collisions with fence and power lines were not an important cause of mortality in this study but may be important in other areas (Wolfe et al. 2007). Overall, low rates of survival among incubating females during the breeding season and higher rates of survival in the nonbreeding season may be a general feature of ground-nesting grouse and waterfowl (Kirby and Cowardin 1986, DeVries et al. 2003, Hagen et al. 2007).

Annual estimates of apparent survival obtained from Cormack-Jolly-Seber models for live encounter data $(42 \%)$ were comparable to return rates previously reported for female Greater PrairieChickens (41-56\%, Hamerstrom and Hamerstrom 1973; 24-57\%, Wisdom and Mills 1997), but improve upon previous estimates of return rates by controlling for probability of encounter (Sandercock 2006). Annual survival of female Greater PrairieChickens was comparable to published estimates for female Lesser Prairie-Chickens (30-50\%, Hagen et al. 2007), and male Lesser Prairie-Chickens (36-60\%, Hagen et al. 2005), but lower than male Greater Prairie-Chickens in the same study population (55-58\%, Nooker and Sandercock 2008 ). Our estimates of apparent survival could be biased low if radio-transmitters negatively affected the survival of females or if there was substantial emigration from our study site (Hagen et al. 2006, Sandercock 2006, Mong and Sandercock 2007). Radio-transmitters are not likely to have affected our results because similar transmitters did not reduce the survival of Lesser Prairie-Chickens (Hagen et al. 2006). The necklace transmitters used in this study were lighter and less restrictive than the backpack transmitters used in early studies of Greater Prairie-Chickens (Burger et al. 1991). We partially accounted for permanent emigration from our study site by using time-since-marking models that partition survival estimates between the time interval after first capture from subsequent intervals (Sandercock 2006). Comparisons to published values and our population modeling both suggest that adult survival was the only demographic rate not depressed by predation.

We estimated that even if all juveniles survived to adulthood, the population would continue to decline given our estimates of other demographic parameters. Empirical estimates of the probability of juvenile survival are more likely to be $<0.38$ (Lesser Prairie-Chickens: 0.124, Pitman et al. 2006; Greater Prairie-Chickens: 0.38, Wisdom and Mills 1997). Therefore, the Greater Prairie-Chicken population examined in this study is unlikely to be maintained by current levels of fecundity and survival, which is consistent with long-term declines in population numbers. Mortality of juvenile grouse increases with intensity of resource extraction, agriculture, and grazing (Hannon and Martin 2006). If few food resources are available, broods may concentrate in a small number of areas with suitable habitats, increasing both competition and risk of predation. Every effort should be taken to create large areas with high quality forage and suitable cover to ensure adequate rates of nest and brood success.

Prairie-chicken movements in our study area were similar to published estimates from other locations. Our estimates of home ranges of female prairiechickens (MCP: 413 ha; 95\% kernel estimates: 575 ha) were similar to previous estimates for birds in Colorado (213-624 ha using 75\% probability contours; Schroeder 1991). Our estimates may be biased low because relatively few positions per female and a small sample of females were used to estimate home range size. However, previous studies have shown that the number of locations is not as important as number of individuals (Girard et al. 2006), so future studies should focus on fitting transmitters on as many birds as possible.

In the past 25 years, Greater Prairie-Chicken populations have received growing attention as a grassland bird of conservation concern (Schroeder 
and Robb 1993). Prairie-chickens have economic value, both as an upland gamebird for hunters, and for viewing opportunities by recreational bird watchers. Unfortunately, current management of the species is largely based on demographic estimates that do not reflect land use changes or statistical advances during the past 30 years. Working in the core of the extant range of Greater Prairie-Chickens, we obtained new estimates of demographic rates that are biologically meaningful and account for the variation in the probability of encounter (Dinsmore et al. 2002, Sandercock 2006). Our empirical results complement population models that have identified low nesting success as the primary demographic factor limiting population viability in lek-mating grouse (Wisdom and Mills 1997, Robel et al. 2003, Stiver et al. 2008, Hagen et al. 2009). Our findings of low productivity, female survival during the breeding season, and juvenile survival from independence to spring indicate an urgent need for effective management techniques to maintain stable populations of Greater Prairie-Chickens in the northern Flint Hills of Kansas. Our 4-year study was based on a single field site near Manhattan, Kansas, and additional research is needed to determine if prairie-chicken demography varies among different ecoregions in Kansas or elsewhere within the range of the species. Land cover in the Flint Hills of Kansas is currently changing because of encroachment of woody plants, increased development of wind power resources, and loss of Conservation Reserve Program (CRP) acreage in favor of ethanol-producing crops. Rangeland practices that increase residual nesting cover or reduce predator impacts are needed, as well as experimental tests to investigate interactions between predation and nesting cover as the proximate mechanisms mediating variation in survival of nests and breeding females. In particular, investigations of how demographic rates of prairie grouse are affected by cattle production in native grasslands, including patch-burn/grazing, intensive early stocking, and moderate burning/grazing, will be critical for development of improved rangeland management strategies for the future.

Responses to this article can be read online at: http://www.ace-eco.org/volb/iss 1/art2/responses/

\section{Acknowledgments:}

We thank the following organizations and people for allowing access to their prairie-chicken leks: Konza Prairie Biological Station, a property of The Nature Conservancy managed by the Division of Biology at Kansas State University; Rannells Flint Hills Prairie Preserve managed by Clenton Owensby in the Department of Agronomy at Kansas State University; and private lands owned by Grant Poole and James Hess. Tom VanSlyke and Kenny Berg provided logistical support. We thank Tracey Adamson, Jeremy Baumgardt, Amanda Behnke, Jarrod Bowers, Tara Conkling, Seth Cutright, DeVaughn Fraser, Chris Frey, Kyle Gerstner, Chod Hedinger, 'Hoogy' Hoogheem, Nichole Lambrecht, and Kara Oberle for field assistance. Expert statistical assistance was provided by Thomas Loughin. Funding for field work included: a NSF Kansas EPSCOR Grant, a research grant from the American Ornithologists' Union, and an NSF Doctoral Dissertation Improvement Grant

(DEB-0608477). J. K. Augustine (née Nooker) was supported by the Konza Prairie NSF Long-Term Ecological Research Grant (DEB-0218210) and by the Division of Biology at Kansas State University. The research was conducted under the following permits: Scientific, Education or Exhibition Wildlife Permit, Kansas Department of Wildlife and Parks (SC-118-2003, SC-068-2004, SC-078-2005, SC-072-2006), and Institutional Animal Care and Use Committee (Protocols 2079, 2351).

\section{LITERATURE CITED}

Aldridge, C. L., and R. M. Brigham. 2001. Nesting and reproductive activities of Greater Sage-Grouse in a declining northern fringe population. Condor 103:537-543.

Applegate, R. D., and G. J. Horak. 1999. Status and management of the Greater Prairie Chicken in Kansas. Pages 113-122 in W. D. Svedarsky, R. H. Hier, and N. J. Silvy, editors. The Greater Prairie Chicken: a national look. Agricultural Experiment Station Miscellaneous Publication 99-1999, University of Minnesota, St. Paul, Minnesota, USA. 
Atamian, A. T., and J. S. Sedinger. 2010. Balanced sex ratio at hatch in a Greater Sage-Grouse (Centrocercus urophasianus) population. Auk 127:16-22.

Barg, J. J., J. Jones, and R. J. Robertson. 2005. Describing breeding territories of migratory passerines: suggestions for sampling, choice of estimator, and delineation of core areas. Journal of Animal Ecology 74:139-149.

Bowker, G., C. Bowker, and D. Baines. 2007. Survival rates and causes of mortality in Black Grouse Tetrao tetrix at Lake Vyrnwy, North Wales, UK. Wildlife Biology 13:231-237.

Brennan, L. A., and W. P. Kuvlesky, Jr. 2005. North American grassland birds: an unfolding conservation crisis? Journal of Wildlife Management 69:1-13.

Bumann, G. B., and D. R. Stauffer. 2002. Scavenging of Ruffed Grouse in the Appalachians: influence and implications. Wildlife Society Bulletin $30: 853-860$.

Burger, Jr., L. W., M. R. Ryan, D. P. Jones, and A. P. Wywialowski. 1991. Radio transmitters bias estimation of movements and survival. Journal of Wildlife Management 55:693-697.

Burnham, K. P., and D. R. Anderson. 2002. Model selection and multimodel inference: a practical information-theoretic approach. Second edition. Springer, New York, New York, USA.

Coates, P. S., and D. J. Delehanty. 2010. Nest predation of Greater Sage-Grouse in relation to microhabitat factors and predators. Journal of Wildlife Managment 74:240-248.

Cooch, E., and G. White. 2009. Program Mark: a gentle introduction. Eighth edition. [online] URL: http://www.phidot.org/software/mark/docs/book/.

DeVries, J. H., J. J. Citta, M. S. Lindberg, D. W. Howerter, and M. G. Anderson. 2003. Breedingseason survival of Mallard females in the prairie pothole region of Canada. Journal of Wildlife Management 67:551-563.

Dinsmore, S. J., G. C. White, and F. L. Knopf. 2002. Advanced techniques for modeling avian nest survival. Ecology 83:3476-3488.
Dusek, G. L., C. D. Eustace, and J. G. Peterson. 2002. The ecology and status of Sage Grouse in Montana. Intermountain Journal of Science $8: 67-81$.

Fletcher, K., N. J. Aebischer, D. Baines, R. Foster, and A. N. Hoodless. 2010. Changes in breeding success and abundance of ground-nesting moorland birds in relation to the experimental deployment of legal predator control. Journal of Applied Ecology 47:263-272.

Girard, I., C. Dussault, J.-P. Ouellet, R. Courtois, and A. Caron. 2006. Balancing number of locations with number of individuals in telemetry studies. Journal of Wildlife Management 70:1249-1256.

Girard, I., J.-P. Ouellet, R. Courtois, C. Dussault, and L. Breton. 2002. Effects of sampling effort based on GPS telemetry on home-range size estimations. Journal of Wildlife Management 66:1290-1300.

Gitzen, R. A., and J. J. Millspaugh. 2003. Comparison of least-squares cross-validation bandwidth options for kernel home-range estimation. Wildlife Society Bulletin 31:823-831.

Green, R. E. 1989. Transformation of crude proportions of nests that are successful for comparison with Mayfield estimates of nest success. Ibis 131:305-306.

Hagen, C. A., J. C. Pitman, B. K. Sandercock, R. J. Robel, and R. D. Applegate. 2005. Age-specific variation in apparent survival rates of male Lesser Prairie-Chickens. Condor 107:78-86.

Hagen, C. A., J. C. Pitman, B. K. Sandercock, R. J. Robel, and R. D. Applegate. 2007. Age-specific survival and probable causes of mortality in female Lesser Prairie-Chickens. Journal of Wildlife Management 71:518-525.

Hagen, C. A., B. K. Sandercock, J. C. Pitman, R. J. Robel, and R. D. Applegate. 2006. Radiotelemetry survival estimates of Lesser Prairie-Chickens in Kansas: are there transmitter biases? Wildlife Society Bulletin 34:1064-1069.

Hagen, C. A., B. K. Sandercock, J. C. Pitman, R. J. Robel, and R. D. Applegate. 2009. Spatial variation 
in Lesser Prairie-Chicken demography: a sensitivity analysis of population dynamics and management alternatives. Journal of Wildlife Management 73:1325-1332.

Hamerstrom, Jr., F. N. 1939. A study of Wisconsin Prairie Chicken and Sharp-Tailed Grouse. Wilson Bulletin 51:105-120.

Hamerstrom, Jr., F. N., and F. Hamerstrom. 1973. The Prairie Chicken in Wisconsin: highlights of a 22-year study of counts, behavior, movements, turnover and habitat. Wisconsin Department of Natural Resources, Technical Bulletin No. 64. Madison, Wisconsin, USA. [online] URL: http://di gital.library.wisc.edu/1711.dl/EcoNatRes.DNRBull64

Hannon, S. J., and K. Martin. 2006. Ecology of juvenile grouse during the transition to adulthood. Journal of Zoology 269:422-433.

Hartke, K. M., J. B. Grand, G. R. Hepp, and T. H. Folk. 2006. Sources of variation in survival of breeding female wood ducks. Condor 108:201-210.

Hooge, P. N., and W. Eichenlaub. 2000. Animal movement extension to ArcView. Version 2.0. Alaska Science Center-Biological Science Office, U.S. Geological Survey, Anchorage, Alaska, USA. [online] URL: http://www.absc.usgs.gov/glba/gistools/ index.htm.

Horak, G. J. 1985. Kansas Prairie Chickens. Kansas Fish and Game Commission, Emporia, Kansas, USA.

Kirby, R. E., and L. M. Cowardin. 1986. Spring and summer survival of female Mallards from northcentral Minnesota. Journal of Wildlife Management 50:38-43.

Konza Prairie Long Term Ecological Research Program. 2004. APT02 Monthly temperature and precipitation records of Manhattan, KS. [online] URL: http://www.konza.ksu.edu/data catalog/toc.html

Lockwood, M. A., C. P. Griffin, M. E. Morrow, C. J. Randel, and N. J. Silvy. 2005. Survival, movements, and reproduction of released captivereared Attwater's Prairie-Chicken. Journal of Wildlife Management 69:1251-1258.
Lutz, R. S., J. S. Lawrence, and N. J. Silvy. 1994. Nesting ecology of Attwater's Prairie-Chicken. Journal of Wildlife Management 58:230-233.

Mayfield, H. F. 1975. Suggestions for calculating nest success. Wilson Bulletin 87:456- 466.

McNew, L. B., A. J. Gregory, S. M. Wisely, and B. K. Sandercock. 2009. Estimating the stage of incubation for nests of Greater Prairie-Chickens using egg flotation: a float curve for grousers. Grouse News 38:12-14.

McNew, L. B., A. J. Gregory, S. M. Wisely, and B. K. Sandercock. 2011. Reproductive chronology and breeding ecology of Greater Prairie-Chickens in Kansas. Studies in Avian Biology, in press.

Millspaugh, J. J., and J. M. Marzluff, editors. 2001. Radio tracking and animal populations. Academic Press, San Diego, California, USA.

Mong, T. W., and B. K. Sandercock. 2007. Optimizing radio retention and minimizing radio impacts in a field study of Upland Sandpipers. Journal of Wildlife Management 71:971-980.

Moss, R., A. Watson, and R. Parr. 1975. Maternal nutrition and breeding success in Red Grouse (Lagopus lagopus scoticus). Journal of Animal Ecology 44:233-244.

Moss, R., A. Watson, P. Rothery, and W. W. Glennie. 1981. Clutch size, egg size, hatch weight and laying date in relation to early mortality in Red Grouse Lagopus lagopus scoticus chicks. Ibis 123:450-462.

Murray, D. L. 2006. On improving telemetry-based survival estimation. Journal of Wildlife Management 70:1530-1543.

Nams, V. O. 2000. Locate II: a program to triangulate radiotelemetry bearing and calculate error ellipses. [online] URL: http://nsac.ca/envsci/s taff/vnams/Locate.htm.

Nooker, J. K. 2007. Factors affecting the demography of a lek-mating bird: the Greater Prairie-Chicken. Dissertation, Kansas State University, Manhattan, Kansas, USA. 
Nooker, J. K., and B. K. Sandercock. 2008. Phenotypic correlates and survival consequences of male mating success in lek-mating Greater PrairieChickens (Tympanuchus cupido). Behavioral Ecology and Sociobiology 62:1377-1388.

Peterson, M. J., W. I. Grant, and N. J. Silvy. 1998. Simulation of reproductive stages limiting productivity of the endangered Attwater's Prairie Chicken. Ecological Modelling 111:283-295.

Peterson, M. J., and N. J. Silvy. 1996. Reproductive stages limiting productivity of the endangered Attwater's Prairie Chicken. Conservation Biology 10:1264-1276.

Pitman, J. C., C. A. Hagen, B. E. Jamison, R. J. Robel, T. M. Loughin, and R. D. Applegate. 2006. Survival of juvenile Lesser Prairie-Chickens in Kansas. Wildlife Society Bulletin 34:675-681.

Pitman, J. C., C. A. Hagen, R. J. Robel, T. M. Loughin, and R. D. Applegate. 2005. Location and success of Lesser Prairie-Chicken nests in relation to vegetation and human disturbance. Journal of Wildlife Management 69:1259-1269.

Powell, L. A. 2007. Approximating variance of demographic parameters using the delta method: a reference for avian biologists. Condor 109:949-954.

Pruett, C. L., M. A. Patten, and D. H. Wolfe. 2009. Avoidance behavior by prairie grouse: implications for development of wind energy. Conservation Biology 23:1253-1259.

Rintamäki, P. T., A. Lundberg, R. V. Alatalo, and J. Höglund. 1998. Assortative mating and female clutch investment in Black Grouse. Animal Behaviour 56:1399-1403.

Robb, L. A., K. Martin, and S. J. Hannon. 1992. Spring body condition, fecundity and survival in female Willow Ptarmigan. Journal of Animal Ecology 61:215-223.

Robbins, M. B., A. T. Peterson, and M. A. OrtegaHuerta. 2002. Major negative impacts of early intensive cattle stocking on tallgrass prairies: the case of the Greater Prairie-Chicken (Tympanuchus cupido). North American Birds 56:239-244.

Robel, R. J. 1966. Booming territory size and mating success of the Greater Prairie Chicken
(Tympanuchus cupido pinnatus). Animal Behaviour 14:328-331.

Robel, R. J. 1970. Possible role of behavior in regulating Greater Prairie Chicken populations. Journal of Wildlife Management 34:306-312.

Robel, R. J., and W. B. Ballard, Jr. 1974. Lek social organization and reproductive success in the Greater Prairie Chicken. American Zoologist 14:121-128.

Robel, R. J., T. L. Walker, Jr., C. A. Hagen, R. K. Ridley, K. E. Kemp, and R. D. Applegate. 2003. Helminth parasites of Lesser Prairie-Chicken Tympanuchus pallidicinctus in southwestern Kansas: incidence, burdens and effects. Wildlife Biology 9:341-349.

Ross, J. D., A. D. Arndt, R. F. C. Smith, J. A. Johnson, and J. L. Bouzat. 2006. Re-examination of the historical range of the Greater Prairie Chicken using provenance data and DNA analysis of museum collections. Conservation Genetics 7:735-750.

Rotella, J. J., S. J. Dinsmore, and T. L. Shaffer. 2004. Modeling nest-survival data: a comparison of recently developed methods that can be implemented in MARK and SAS. Animal Biodiversity and Conservation 27(1):187-205.

Ryan, M. R., L. W. Burger, Jr., D. P. Jones, and A. P. Wywialowski. 1998. Breeding ecology of Greater Prairie-Chickens (Tympanuchus cupido) in relation to prairie landscape configuration. American Midland Naturalist 140:111-121.

Samson, F., and F. Knopf. 1994. Prairie conservation in North America. BioScience $44: 418-421$.

Sandercock, B. K. 2006. Estimation of demographic parameters from live-encounter data: a summary review. Journal of Wildlife Management 70:1504-1520.

Sandercock, B. K., W. E. Jensen, C. K. Williams, and R. D. Applegate. 2008. Demographic sensitivity of population change in the Northern Bobwhite. Journal of Wildlife Management 72:970-982.

Sandercock, B. K., K. Martin, and S. J. Hannon. 2005. Demographic consequences of age-structure in extreme environments: population models for arctic and alpine ptarmigan. Oecologia 146:13-24. 
Sandercock, B. K., and H. C. Pedersen. 1994. The effect of renesting ability and nesting attempt on egg-size variation in Willow Ptarmigan. Canadian Journal of Zoology 72:2252-2255.

Schroeder, M. A. 1991. Movement and lek visitation by female Greater Prairie-Chickens in relation to predictions of Bradbury's female preference hypothesis of lek evolution. Auk 108:896-903.

Schroeder, M. A., and R. K. Baydack. 2001. Predation and the management of prairie grouse. Wildlife Society Bulletin 29:24-32.

Schroeder, M. A., and C. E. Braun. 1991. Walk-in traps for capturing Greater Prairie-Chickens on leks. Journal of Field Ornithology 62:378-385.

Schroeder, M. A., and L. A. Robb. 1993. Greater Prairie-Chicken (Tympanuchus cupido). In A. Poole, P. Stettenheim, and F. Gill, editors. Birds of North America, Number 36. American Ornithologists' Union, Washington, D.C., USA, and Academy of Natural Sciences, Philadelphia, Pennsylvania, USA. [online] URL: http://bna.birds.cornell.edu/bna/ species/036/articles/introduction.

Seaman, D. E., J. J. Millspaugh, B. J. Kernohan, G. C. Brundige, K. J. Raedeke, and R. A. Gitzen. 1999. Effects of sample size on kernel home range estimates. Journal of Wildlife Management 63:739-747.

Seaman, D. E., and R. A. Powell. 1996. An evaluation of the accuracy of kernel density estimators for home range analysis. Ecology 77:2075-2085.

Silvy, N. J., M. J. Peterson, and R. R. Lopez. 2004. The cause of the decline of pinnated grouse: the Texas example. Wildlife Society Bulletin 32:16-21.

Stiver, J. R., A. D. Apa, T. E. Remington, and R. M. Gibson. 2008. Polygyny and female breeding failure reduce effective population size in the lekking Gunnison Sage-Grouse. Biological Conservation 141:472-481.

Svedarsky, W. D., R. L. Westemeier, R. J. Robel, S. Gough, and J. E. Toepfer. 2000. Status and management of the Greater Prairie-Chicken
Tympanuchus cupido pinnatus in North America. Wildlife Biology 6:277-284.

Warren, P. K., and D. Baines. 2002. Dispersal, survival and causes of mortality in Black Grouse Tetrao tetrix in northern England. Wildlife Biology 8:91-97.

Westemeier, R. L., J. E. Buhnerkempe, and J. D. Brawn. 1998a. Effects of flushing nesting Greater Prairie-Chickens in Illinois. Wilson Bulletin 110:190-197.

Westemeier, R. L., J. E. Buhnerkempe, W. R. Edwards, J. D. Brawn, and S. A. Simpson. 1998b. Parasitism of Greater Prairie-Chicken nests by Ring-necked Pheasants. Journal of Wildlife Management 62:854-863.

White, G. C., and K. P. Burnham. 1999. Program MARK: survival estimation from populations of marked animals. Bird Study 46(Suppl):S120-S139.

White, G. C., K. P. Burnham, and D. R. Anderson. 2001. Advanced features of Program Mark. Pages 368-377 in R. Field, R. J. Warren, H. Okarma, and P. R. Sievert, editors. Wildlife, land, and people: Priorities for the 21st century. The Wildlife Society, Bethesda, Maryland, USA.

Wisdom, M. J., and L. S. Mills. 1997. Sensitivity analysis to guide population recovery: prairiechickens as an example. Journal of Wildlife Management 61:302-312.

Wolfe, D. H., M. A. Patten, E. Shochat, C. L. Pruett, and S. K. Sherrod. 2007. Causes and patterns of mortality in Lesser Prairie-Chickens Tympanuchus pallidicinctus and implications for management. Wildlife Biology 13(Suppl 1):95-104. 